\title{
Correlation of the plasma level of insulin-like growth factor-1 with the number of aberrant crypt foci in male individuals
}

\author{
HIROKAZU TAKAHASHI ${ }^{1}$, TETSUJI TAKAYAMA ${ }^{2}$, KUNIHIRO HOSONO $^{1}$, KYOKO YONEDA $^{1}$, HIROKI ENDO $^{1}$, \\ YUICHI NOZAKI ${ }^{1}$, KOJI FUJITA ${ }^{1}$, MASATO YONEDA ${ }^{1}$, MASAHIKO INAMORI ${ }^{1}$, YASUNOBU ABE ${ }^{1}$, \\ NORITOSHI KOBAYASHI ${ }^{1}$, HIROYUKI KIRIKOSHI ${ }^{1}$, KENSUKE KUBOTA $^{1}$, SATORU SAITO $^{1}$, \\ HITOSHI NAKAGAMA $^{3}$ and ATSUSHI NAKAJIMA ${ }^{1}$ \\ ${ }^{1}$ Division of Gastroenterology, Yokohama City University Graduate School of Medicine, Yokohama; \\ ${ }^{2}$ Division of Gastroenterology, University of Tokushima Faculty of Medicine, Tokushima; \\ ${ }^{3}$ Division of Biochemistry, National Cancer Center Research Institute, Tokyo, Japan
}

Received 29 October, 2008; Accepted February 20, 2009

DOI: 10.3892/mmr_00000105

\begin{abstract}
In human subjects, aberrant crypt foci (ACF) can be classified as dysplastic or non-dysplastic using magnifying colonoscopy. Dysplastic ACF are thought to be a biomarker for the risk of colorectal cancer (CRC). Hyperinsulinemia and insulin-like growth factor-1 (IGF-1) have also been reported to be associated with an increased risk of CRC. To clarify this association, we investigated the relationship between diabetes risk, IGF-1 and the number of dysplastic ACF. Assessment of the number of dysplastic ACF in the entire colorectum is technically difficult, and we imaged the lower rectum only. Blood collections were taken in the morning on the day of colonoscopy. A total of 512 ACF were counted in 84 male participants, and a correlation was demonstrated to exist between age, body mass index (BMI), fasting blood sugar (FBS), insulin, homeostasis model assessment-insulin resistance (HOMA-IR), plasma leptin levels, plasma IGF-1 levels and the number of dysplastic ACF. A significant association between plasma IGF-1 levels and the number of dysplastic $\mathrm{ACF}$ was still demonstrable after adjustment for age, BMI, FBS, insulin, HOMA-IR and plasma leptin levels. Our findings suggest that increased plasma leptin and IGF-1 levels, hyperinsulinemia and insulin resistance may promote the growth of dysplastic ACF. The results of multiple regression analysis
\end{abstract}

Correspondence to: Dr Hirokazu Takahashi, Division of Gastroenterology, Yokohama City University Graduate School of Medicine, 3-9 Fukuura, Kanazawa-ku, Yokohama 236-0004, Japan

E-mail: hirokazu@med.yokohama-cu.ac.jp

Abbreviations: ACF, aberrant crypt foci; BMI, body mass index; CRC, colorectal cancer; FBS, fasting blood sugar; HOMA-IR, homeostasis model assessment-insulin resistance; IGF-1, insulinlike growth factor-1

Key words: aberrant crypt foci, colorectal carcinogenesis, insulinlike growth factor-1 revealed that increased plasma IGF-1 levels are associated with the number of dysplastic ACF present, and may be an independent risk factor for CRC. In conclusion, elevated plasma IGF-1 may promote the growth of dysplastic ACF and play a key role in colon carcinogenesis in male individuals.

\section{Introduction}

Colorectal cancer (CRC) has a high mortality and morbidity rate, and its prevalence worldwide is increasing $(1,2)$. The precise risk factors for CRC remain unknown, although a positive family history and several dietary and lifestyle factors have been proposed (3). In the present study, we aimed to investigate several risk factors for colon carcinogenesis by employing ACF, which are a known biomarker for the risk of CRC.

ACF were first identified in mice treated with azoxymethane (4), and have since been established as a biomarker for the risk of $\mathrm{CRC}$ in azoxymethane-treated mice and rats (5). In humans, ACF can be classified as dysplastic or nondysplastic using magnifying colonoscopy (6). While ACF have not, in general, been firmly established as precursor lesions of CRC, dysplastic ACF are thought to be a reasonably reliable biomarker of CRC risk (6).

If hyperinsulinemia, alone or in combination with other characteristics of the insulin resistance syndrome, is associated with an increased risk of CRC, it too may play a key role in colon carcinogenesis. However, the association between type 2 diabetes mellitus (DM) and the risk of CRC has not been thoroughly examined, although a recent study reported an increased prevalence of colonic adenomas in diabetic patients (7). Insulin, similar to insulin-like growth factor-1 (IGF-1), stimulates the growth of both normal colon and colon cancer cells in vitro $(8,9)$. Furthermore, the expression of both insulin and IGF-1 receptors has been demonstrated in CRC $(10,11)$. Nevertheless, the relationship between hyperinsulinemia or insulin resistance and colon carcinogenesis remains unclear.

To clarify this association, we investigated the relationship between the plasma levels of IGF-1 and numbers of dysplastic $\mathrm{ACF}$, since the latter is thought to be a biomarker of the risk 
of CRC. In young adults, IGF-1 levels are higher in female individuals. However, by midlife, males exhibit higher plasma IGF-I levels than females $(12,13)$. These differences may be influenced by sex hormones, which show dramatic changes around menopause in females. Plasma IGF-1 also declines linearly with age in male individuals, but not in females, prompting us to design this study for male subjects alone. We investigated the relationship between the plasma levels of insulin, insulin resistance and the numbers of dysplastic ACF (14).

\section{Patients and methods}

Study sample. The study protocol was approved by the Yokohama City University Hospital Ethics Committee. We prospectively evaluated 84 consecutive male subjects who underwent colonoscopy at Yokohama City University Hospital, Japan. The exclusion criteria were: presence of contraindications to colonoscopy, current or past history of the use of non-steroidal anti-inflammatory drugs including aspirin, and a history of adenoma, carcinoma, familial adenomatous polyposis, inflammatory bowel disease, radiation colitis, oral anti-hyperglycemic drug use or insulin therapy. Subects with a history of colectomy, gastrectomy and colorectal polypectomy were also excluded. Written informed consent was obtained from all the subjects prior to their participation in the study.

Collection and analysis of blood samples for leptin and IGF-1 levels. Blood samples were obtained in the morning on the day of colonoscopy after overnight fasting. Plasma leptin and IGF-1 levels were measured by SRL Co. Ltd. (Tokyo, Japan).

Demographic, lifestyle and clinical data. Immediately before the colonoscopy, a detailed history was obtained from the participants, and their age, height and weight was recorded.

Magnifying colonoscopy for aberrant crypt foci. Participants were prepared with polyethylene glycol for the magnifying colonoscopy. A Fujinon EC-490ZW5/M colonoscope was used (Fujinon Toshiba ES Systems Co., Ltd., Tokyo, Japan). Total colonoscopy was performed prior to the imaging of rectal ACF. Subsequently, $0.25 \%$ methylene blue was applied to the mucosa with a spray catheter. Based on the results of a previous study (6), ACF were counted in the lower rectal region, from the middle Houston valve to the dentate line. We relied on endoscopic criteria to confirm dysplastic ACF, as it is very difficult to do so pathologically due to the very small size of these lesions, which complicates sampling by colonoscopy and the precision of slicing. In addition to the technical difficulties involved, it was necessary to consider the increased burden that a sampling procedure would place on the participants. All ACF were recorded photographically and evaluated by two independent observers, both unaware of the clinical history of the subjects.

Criteria for endoscopic diagnosis. ACF were defined as lesions in which the crypts were larger in diameter and showed darker staining with methylene blue than normal crypts, often having oval or slit-like lumens and a thicker epithelial lining (15-18). Dysplastic ACF were defined as crypts with com-

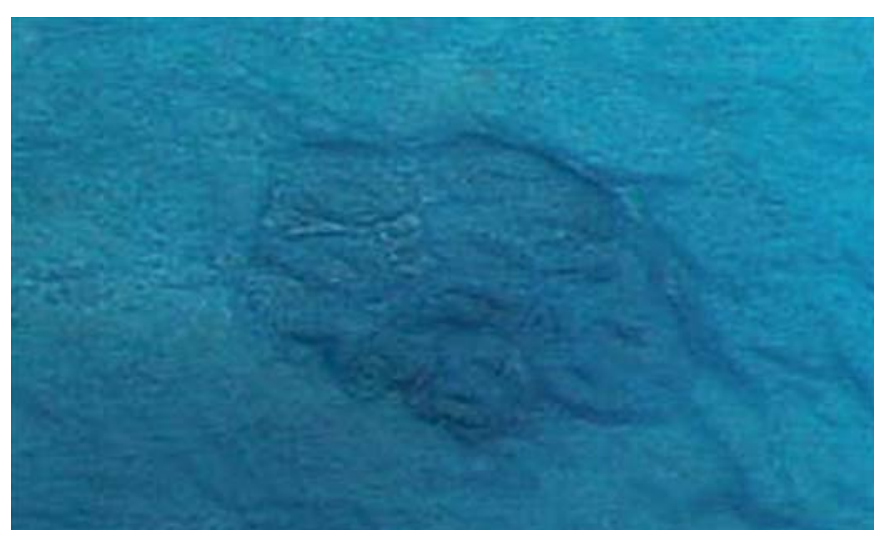

Figure 1. Typical features of dysplastic ACF using magnifying colonoscopy after methylene blue staining.

pressed or indistinct lumina, with an epithelial lining much thicker than that of the surrounding normal crypts as detected by magnifying colonoscopy (Fig. 1).

Statistical analysis. The association between the risk factors for CRC and the number of dysplastic ACF was examined by statistical analysis. Data are expressed as the mean \pm standard deviation (SD), unless otherwise indicated. The relationship between the number of dysplastic ACF and the relevant covariates was examined by univariate regression analysis. Standardized correlation coefficients were determined with StatView software (SAS Institute Inc., Cary, NC, USA). Multiple regression analysis was performed to assess the relationship between the number of dysplastic ACF and the potentially associated variables, and to determine the standardized correlation coefficients. The dependent variable was the number of dysplastic ACF, and the independent variables were age, body mass index (BMI), fasting blood sugar (FBS), insulin, homeostasis model assessment-insulin resistance (HOMA-IR), plasma IGF-1 and leptin levels. $\mathrm{P}<0.05$ was considered to denote statistical significance.

\section{Results}

Colonoscopic features of aberrant crypt foci. A total of 512 ACF, including 99 dysplastic ACF, were counted by magnifying colonoscopy in the 84 male patients. Dysplastic and non-dysplastic ACF accounted for $19.3 \%$ (99/512) and $80.7 \%$ (413/512) of the total number of ACF, respectively.

Patient characteristics. The clinical characteristics of the study participants are shown in Table I. The mean $( \pm$ SD) age was $66.0 \pm 10.6$ years. The mean BMI, FBS, HbA1c, insulin, HOMA-IR, serum total cholesterol, serum triglyceride, plasma IGF-1 and plasma leptin levels were $23.4 \pm 3.5 \mathrm{~kg} / \mathrm{m}^{2}$, $113.2 \pm 28.9 \mathrm{mg} / \mathrm{dl}, 5.56 \pm 0.77 \%, 5.46 \pm 4.85 \mu \mathrm{U} / \mathrm{ml}, 1.49 \pm 1.35$, $204.2 \pm 34.2 \mathrm{mg} / \mathrm{dl}, 166.2 \pm 188.0 \mathrm{mg} / \mathrm{dl}, 125.8 \pm 39.1 \mathrm{ng} / \mathrm{ml}$ and $4.83 \pm 4.71 \mathrm{ng} / \mathrm{ml}$, respectively.

Univariate regression analysis for correlations between colorectal cancer risk factors and the number of non-dysplastic or dysplastic aberrant crypt foci. Age and BMI were correlated with the number of dysplastic ACF, as shown in Table II (age: 
Table I. Clinical characteristics of study participants.

\begin{tabular}{lc}
\hline Age (years) & $66.0 \pm 10.6$ \\
BMI $\left(\mathrm{kg} / \mathrm{m}^{2}\right)$ & $23.4 \pm 3.5$ \\
FBS $(\mathrm{mg} / \mathrm{dl})$ & $113.2 \pm 28.9$ \\
HbA1c $(\%)$ & $5.56 \pm 0.77$ \\
Insulin $(\mu \mathrm{U} / \mathrm{ml})$ & $5.46 \pm 4.85$ \\
HOMA-IR & $1.49 \pm 1.35$ \\
Total cholesterol $(\mathrm{mg} / \mathrm{dl})$ & $204.2 \pm 34.2$ \\
Triglyceride $(\mathrm{mg} / \mathrm{dl})$ & $166.2 \pm 188.0$ \\
Plasma IGF-1 $(\mathrm{ng} / \mathrm{ml})$ & $125.8 \pm 39.1$ \\
Plasma leptin $(\mathrm{ng} / \mathrm{ml})$ & $4.83 \pm 4.71$ \\
\hline
\end{tabular}

Data are expressed as the mean $\pm \mathrm{SD} ; \mathrm{n}=84$.

Table II. Univariate regression analysis to determine correlations between the number of non-dysplastic or dysplastic $\mathrm{ACF}$ and $\mathrm{CRC}$ risk factors.

\begin{tabular}{|c|c|c|c|c|}
\hline \multirow[b]{2}{*}{ Risk factors } & \multicolumn{2}{|c|}{$\begin{array}{c}\text { Non-dysplastic } \\
\text { ACF }\end{array}$} & \multicolumn{2}{|c|}{$\begin{array}{c}\text { Dysplastic } \\
\text { ACF }\end{array}$} \\
\hline & r-value & P-value & r-value & P-value \\
\hline Age (years) & 0.249 & $0.0222^{\mathrm{a}}$ & 0.219 & $0.0448^{\mathrm{a}}$ \\
\hline BMI $\left(\mathrm{kg} / \mathrm{m}^{2}\right)$ & 0.068 & 0.5460 & 0.303 & $0.0058^{\mathrm{a}}$ \\
\hline FBS (mg/dl) & 0.137 & 0.2355 & 0.322 & $0.0041^{\mathrm{a}}$ \\
\hline HbA1c (\%) & 0.095 & 0.4362 & 0.227 & 0.0586 \\
\hline Insulin $(\mu \mathrm{U} / \mathrm{ml})$ & 0.140 & 0.2618 & 0.333 & $0.0061^{\mathrm{a}}$ \\
\hline HOMA-IR & 0.146 & 0.2431 & 0.385 & $0.0013^{\mathrm{a}}$ \\
\hline Total cholesterol (mg/dl) & 0.181 & 0.1240 & 0.015 & 0.8965 \\
\hline Triglyceride (mg/dl) & 0.083 & 0.4851 & 0.086 & 0.4694 \\
\hline Plasma IGF-1 (ng/ml) & -0.008 & 0.9430 & 0.258 & $0.0177^{\mathrm{a}}$ \\
\hline Plasma leptin (ng/ml) & 0.088 & 0.4284 & 0.268 & $0.0135^{\mathrm{a}}$ \\
\hline
\end{tabular}

Age was the only parameter that was significantly correlated with the number of non-dysplastic ACF. Age, BMI, FBS, plasma insulin, HOMA-IR, plasma IGF-1 and plasma leptin were correlated with the number of dysplastic ACF. ${ }^{\mathrm{a}} \mathrm{P}<0.05$ was considered to denote statistical significance.

$\mathrm{r}=0.219, \mathrm{P}=0.0448$; BMI: $\mathrm{r}=0.303, \mathrm{P}=0.0058$ ). FBS, plasma insulin and HOMA-IR were correlated with the number of dysplastic ACF (FBS: $r=0.322, P=0.0041$; insulin: $r=0.333$, $\mathrm{P}=0.0061$; HOMA-IR: $\mathrm{r}=0.385, \mathrm{P}=0.0013$ ). The plasma levels of IGF-1 and leptin were correlated with the number of dysplastic ACF (IGF-1: $\mathrm{r}=0.258, \mathrm{P}=0.0177$; leptin: $\mathrm{r}=0.268$, $\mathrm{P}=0.0135$ ). The serum levels of total cholesterol and triglyceride were not correlated with the number of dysplastic ACF. Age was the only parameter that was significantly correlated with the number of non-dysplastic ACF ( $r=0.249$, $\mathrm{P}=0.0222$ ).
Table III. Multiple regression analysis to determine correlations between the number of dysplastic ACF and CRC risk factors.

\begin{tabular}{lcc}
\hline Risk factors & Correlation coefficient & P-value \\
\hline Age (years) & 0.232 & 0.0625 \\
BMI $\left(\mathrm{kg} / \mathrm{m}^{2}\right)$ & 0.166 & 0.3970 \\
FBS $(\mathrm{mg} / \mathrm{dl})$ & -0.131 & 0.5181 \\
Insulin $(\mu \mathrm{U} / \mathrm{ml})$ & -0.565 & 0.4086 \\
HOMA-IR & 0.735 & 0.3092 \\
Plasma IGF-1 $(\mathrm{ng} / \mathrm{ml})$ & 0.272 & $0.0251^{\mathrm{a}}$ \\
Plasma leptin $(\mathrm{ng} / \mathrm{ml})$ & 0.077 & 0.6906 \\
\hline
\end{tabular}

$\mathrm{R}^{2}$ for the entire model $=0.307$. ${ }^{\mathrm{a}} \mathrm{P}<0.05$ was considered to denote statistical significance in the results of multiple regression analysis. After adjustments for age, BMI, FBS, plasma insulin, HOMA-IR and plasma leptin, plasma IGF-1 levels were still statistically significantly correlated with the number of dysplastic ACF.

Multiple regression analysis for correlations between CRC risk factors and the number of dysplastic ACF. The results of multiple regression analysis are shown in Table III. After adjustment for age, BMI, FBS, insulin, HOMA-IR and leptin, IGF-1 was still statistically significantly correlated with the number of dysplastic ACF $(\mathrm{P}=0.0251)$.

\section{Discussion}

Hyperinsulinemia has been linked to a higher incidence of malignancies and/or has been reported to be a predictor of cancer mortality. Insulin has been demonstrated to have some homology to IGF-1; moreover, the two have been shown to have some affinity for tumor growth factor receptors. Hence, the existence of an association between hyperinsulinemia, IGF-1 and carcinogenesis appears plausible (19). Insulin-like growth factors are potent mitogenic and anti-apoptotic molecules involved in the regulation of cell proliferation in various epithelial cells (20).

In this study, a total of 512 ACF were counted in the 84 male participants, and a significant correlation was observed between plasma IGF-1 levels and the number of dysplastic ACF. Age was also associated with the number of nondysplastic and dysplastic ACF. CRC is thought to progress through several morphological stages, from the formation of polyps to the onset of malignant change (21). Therefore, the increased risk of the formation of ACF with age may mainly be influenced by these alterations.

Plasma leptin has been shown to be associated with the number of dysplastic ACF. Moreover, it has been suggested that plasma leptin increases the risk of CRC and acts as a growth factor for CRC cells (22). Hyperinsulinemia is known to be present during the early stages of type 2 DM (23), and pre-clinical studies have indicated that insulin stimulates cellular proliferation, decreases apoptosis, and promotes tumorigenesis within the colorectum (24-27). It thus seems biologically plausible that individuals with hyperinsulinemia 
might be at an increased risk for CRC. A positive association between type $2 \mathrm{DM}$ and colon carcinogenesis has been reported to exist in male individuals (28). Our results revealed a strong correlation between the plasma levels of insulin and HOMA-IR as a measure of insulin resistance and the number of dysplastic ACF in male, but not in female, individuals (data not shown). During the early stages of type 2 DM, hyperinsulinemia results from a combination of insulin resistance and increased insulin secretion (29).

Our data suggest the existence of a direct correlation between plasma IGF-1 levels and the number of dysplastic ACF in males (Table II). Multiple regression analysis was performed to assess whether elevated plasma IGF-1 is associated with the presence of dysplastic ACF. If dysplastic ACF is a biomarker for the risk of colorectal adenoma or CRC, then factors associated with $\mathrm{CRC}$ risk may also influence the number of dysplastic ACF. However, IGF-1, insulin and insulin resistance are also associated with each other, thus IGF-1 is not only an indicator of CRC risk. Insulin increases the release of bioactive IGF-1 by various mechanisms (30). Growth hormones are the primary regulator of IGF-1 production by the liver, and the number of growth hormone receptors in the liver is partly regulated by insulin (31-33). Very little is known regarding the factors that initiate or promote the growth of dysplastic ACF in humans. Further investigation is needed for the precise elucidation of these mechanisms.

In conclusion, our results indicate that plasma IGF-1 may promote dysplastic ACF, which in turn suggests that IGF-1 may play a key role in colorectal carcinogenesis in male individuals. This provides new insight into the mechanisms involved in the disease.

\section{Acknowledgements}

The authors thank Machiko Hiraga for technical assistance. This work was supported in part by a Grant-in-Aid for the Third Term Comprehensive Control Research for Cancer from the Ministry of Health, Labour and Welfare, Japan to A.N., by a grant from the National Institute of Biomedical Innovation (NBIO) to A.N., by a grant from the Ministry of Education, Culture, Sports, Science and Technology, Japan (KIBAN-B) to A.N., by a grant from the Ministry of Education, Culture, Sports, Science and Technology, Japan (WAKATE-B) to H.T., by a research grant from the Princess Takamatsu Cancer Research Fund to A.N., and by a grant for the 2007 Strategic Research Project (No. K19041) of Yokohama City University, Japan to H.T. and A.N.

\section{References}

1. Anderson WF, Umar A and Brawley OW: Colorectal carcinoma in black and white race. Cancer Metastasis Rev 22: 67-82, 2003.

2. Rougier P and Mitry E: Epidemiology, treatment and chemoprevention in colorectal cancer. Ann Oncol 14: 3-5, 2003.

3. Garland C, Shekelle RB, Barrett-Connor E, Criqui MH, Rossof $\mathrm{AH}$ and Paul O: Dietary vitamin D and calcium and risk of colorectal cancer: a 19-year prospective study in men. Lancet i: 307-309, 1985.

4. Bird RP: Observation and quantification of aberrant crypts in the murine colon treated with a colon carcinogen: preliminary findings. Cancer Lett 37: 147-151, 1987.
5. Pretlow TP, O'Riordan MA, Somich GA, Amini SB and Pretlow TG: Aberrant crypts correlate with tumor incidence in F344 rats treated with azoxymethane and phytate. Carcinogenesis 13: 1509-1512, 1992.

6. Takayama T, Katsuki S, Takahashi Y, Ohi M, Nojiri S, Sakamaki S, Kato J, Kogawa K, Miyake H and Niitsu Y: Aberrant crypt foci of the colon as precursors of adenoma and cancer. N Engl J Med 339: 1277-1284, 1998.

7. Elwing JE, Gao F, Davidson NO and Early DS: Type 2 diabetes mellitus: the impact on colorectal adenoma risk in women. Am J Gastroenterol 101: 1866-1871, 2006.

8. Watkins L, Lewis L and Levine A: Characterization of the synergistic effect of insulin and transferring and the regulation of their receptors on a human colon carcinoma cell line. Int $\mathrm{J}$ Cancer 45: 372-375, 1990.

9. Giovannucci E: Insulin, insulin-like growth factors and colon cancer: a review of the evidence. J Nutr 131: S3109-S3120, 2001.

10. Guo YS, Narayan S, Yallampalli C and Singh P: Characterization of insulin-like growth factor 1 receptors in human colon cancer. Gastroenterology 102: 1101-1108, 1992.

11. MacDonald RS, Thornton WH and Bean TL: Insulin and IGF-1 receptors in a human intestinal adenocarcinoma cell line (Caco-2) regulation of Nat glucose transport across the brush border. J Recept Res 13: 1093-1113, 1993.

12. Jørgensen JO, Vahl N, Hansen TB, Skjaerbaek C, Fisker S, Orskov H, Hagen C and Christiansen JS: Determinants of serum insulin-like growth factor I in growth hormone deficient adults as compared with healthy subjects. Clin Endocrinol 48: 479-486, 1998.

13. Landin-Wilhelmsen K, Wilhelmsen L, Lappas G, Rosén T, Lindstedt G, Lundberg PA and Bengtsson BA: Serum insulinlike growth factor I in a random population sample of men and women: relation to age, sex, smoking habits, coffee consumption and physical activity, blood pressure and concentrations of plasma lipids, fibrinogen, parathyroid hormone and osteocalcin. Clin Endocrinol 41: 351-357, 1994.

14. Yamamoto H, Sohmiya M, Oka N and Kato Y: Effects of aging and sex on plasma insulin-like growth factor I (IGF-I) levels in normal adults. Acta Endocrinol 124: 497-500, 1991.

15. Roncucci L, Stamp D, Medline A, Cullen JB and Bruce WR: Identification and quantification of aberrant crypt foci and microadenomas in the human colon. Hum Pathol 22: 287-294, 1991.

16. Roncucci L, Medline A and Bruce WR: Classification of aberrant crypt foci and microadenomas in human colon. Cancer Epidemiol Biomarkers Prev 1: 57-60, 1991.

17. Pretlow TP, Barrow BJ, Ashton WS, O'Riordan MA, Pretlow TG, Jurcisek JA and Stellato TA: Aberrant crypts: putative preneoplastic foci in human colonic mucosa. Cancer Res 51: 1564-1567, 1991.

18. Pretlow TP, O'Riordan MA, Pretlow TG and Stellato TA: Aberrant crypts in human colonic mucosa: putative preneoplastic lesions. J Cell Biochem 16 (Suppl): 55-62, 1992.

19. Schiel R, Beltschikow W, Steiner T and Stein G: Diabetes, insulin, and risk of cancer. Methods Find Exp Clin Pharmacol 28: 169-175, 2006.

20. Pollak M: Insulin-like growth factor physiology and cancer risk. Eur J Cancer 36: 1224-1228, 2000.

21. Kinzler KW and Vogelstein B: Lessons from hereditary colorectal cancer. Cell 87: 159-170, 1996.

22. Aparicio T, Kotelevets L, Tsocas A, Laigneau JP, Sobhani I, Chastre $\mathrm{E}$ and Lehy $\mathrm{T}$ : Leptin stimulates the proliferation of human colon cancer cells in vitro but does not promote the growth of colon cancer xenografts in nude mice or intestinal tumorigenesis in Apc(Min/+) mice. Gut 54: 1136-1145, 2005.

23. De Fronzo RA: Pathogenesis of type 2 diabetes mellitus. Med Clin North Am 88: 787-835, 2004.

24. Koenuma M, Yamori T and Tsuruo T: Insulin and insulin-like growth factor 1 stimulate proliferation of metastatic variants of colon carcinoma 26. Jpn J Cancer Res 80: 51-58, 1989.

25. Wu X, Fan Z, Masui H, Rosen N and Mendelsohn J: Apoptosis induced by an anti-epidermal growth factor receptor monoclonal antibody in a human colorectal carcinoma cell line and its delay by insulin. J Clin Invest 95: 1897-1905, 1995.

26. Tran TT, Medline A and Bruce WR: Insulin promotion of colon tumors in rats. Cancer Epidemiol Biomarkers Prev 5: 1013-1015, 1996.

27. Corpet DE, Jacquinet C, Peiffer G, et al: Insulin injections promote the growth of aberrant crypt foci in the colon of rats. Nutr Cancer 27: 316-320, 1997. 
28. Limburg PJ, Vierkant RA, Fredericksen ZS, Leibson CL Rizza RA, Gupta AK, Ahlquist DA, Melton LJ III, Sellers TA and Cerhan JR: Clinically confirmed type 2 diabetes mellitus and colorectal cancer risk: a population-based, retrospective cohort study. Am J Gastroenterol 101: 1872-1879, 2006.

29. Stumvoll M, Goldstein BJ and van Haeften TW: Type 2 diabetes: principles of pathogenesis and therapy. Lancet 365: 1333-1346, 2005.

30. Pfeifle B, Hamann H, Fussganger R and Ditschuneit H: Insulin as a growth regulator of arterial smooth muscle cells: effect of insulin of I.G.F.I. Diabetes Metab 13: 326-330, 1987
31. Jones $\mathbf{J}$ and Clemmons D: Insulin-like growth factors and their binding proteins: biological actions. Endocr Rev 16: 3-34, 1995. 32. Underwood LE, Thissen JP, Lemozy S, Ketelslegers JM and Clemmons DR: Hormonal and nutritional regulation of IGF-1 and its binding proteins. Horm Res 42: 145-151, 1994.

33. Smith WJ, Underwood LE and Clemmons DR: Effects of caloric or protein restriction on insulin-like growth factor-1 (IGF-1) and IGF binding proteins in children and adults. J Clin Endocrinol Metab 80: 443-449, 1995. 